Diane Sbardelotto

Mestranda

Programa de

em Educação da

FRGS. Licenciad

e Bacharel em Artes

Visuais(UFRGS,

UNOCHAPECÓ).

Artista visua

e professora.

e professor

Integrante Grupo

- Arte, Corpo

EnSigno (CNPq)

\section{Dobrar e continuar}

Quando desaprendi de não dobrar, já estava no meio do processo. No meio de mim, sem fim

infinitamente para dentro

frente a frente a frente a frente a

isso

é sobre

isso

Penso que a mim me cabe esta posição.

Tem sido um tempo de não caber.

Quantas vezes, quantas vezes não quebrei quantas vezes!

Tantas vezes já me repeti e ainda, e por isso, não sei se me dobro ou se me dobram.

Uma mulher me viu.

Perguntei se eu ia resistir.
Dobrar, curvar alguma coisa flexível, submeter alguém ou alguma coisa, forçar, adaptar, mas também: duplicar, fazer o dobro, refletir, repetir, repetir de novo e repetir diferente, abrir o corpo em múltiplos, fechar-se para sair dele, agir na imobilidade, alternar entre o inerte e o volúvel, experimentar do corpo as propriedades que já têm, inventar outras, inventar-se outra, resiliente, dúctil, despir-se como código, desidentificar-se até a carne, ser mulher como potência de variação.

O ensaio aqui apresentado é parte de uma pesquisa acadêmico -poética ${ }^{1}$ e verbo-visual em educação, transversal à arte, filosofia e poesia, onde se explora um corpo feminino - o da própria pesquisadora, como objeto principal - dobrado em experimentações-continuidades. Os estratos corpóreos orgânicos, subjetivos e semióticos do corpo em dobra física são estudados junto ao conceito deleuzo-foucaultiano de dobra, da filosofia da diferença, na qual a dobra é usada para falar dos processos de subjetivação, da força vergada, de si para consigo.

A dobra repete-se no corpo e alterna-se nas situações e nos tempos, ambientes e enquadramentos fotográficos que quebram as próprias regras. Ela abre o corpo e paradoxalmente o fecha em si. Essa posição inventa um olhar da outra de si por um método fotográfico de autorretrato com máquina fotográfica e temporizador, ações chamadas aqui de "fotodobragens".

Trata-se de uma poética que pretende fazer movimentos num "fora", utilizando como matéria um corpo e seus territórios existenciais externos e internos pensados como coextensivos, entre a curvatura do contorno delimitador de um corpo e as paisagens em que se insere.

Tal inserção gera muitos tipos de relação. Do conflito à simbiose, passando por camuflagens, contiguidades, codificações, narrativas, subversões do próprio processo.
[1] Desenvolvida no Mestrado em Educação do Programa de em Educação da UFRGS, linha da UFRGS, linhe
Filosofias da Filosofias da
Diferença, com temática Poéticas temática Poéticas Transversais, sob orientação da Zordan. 


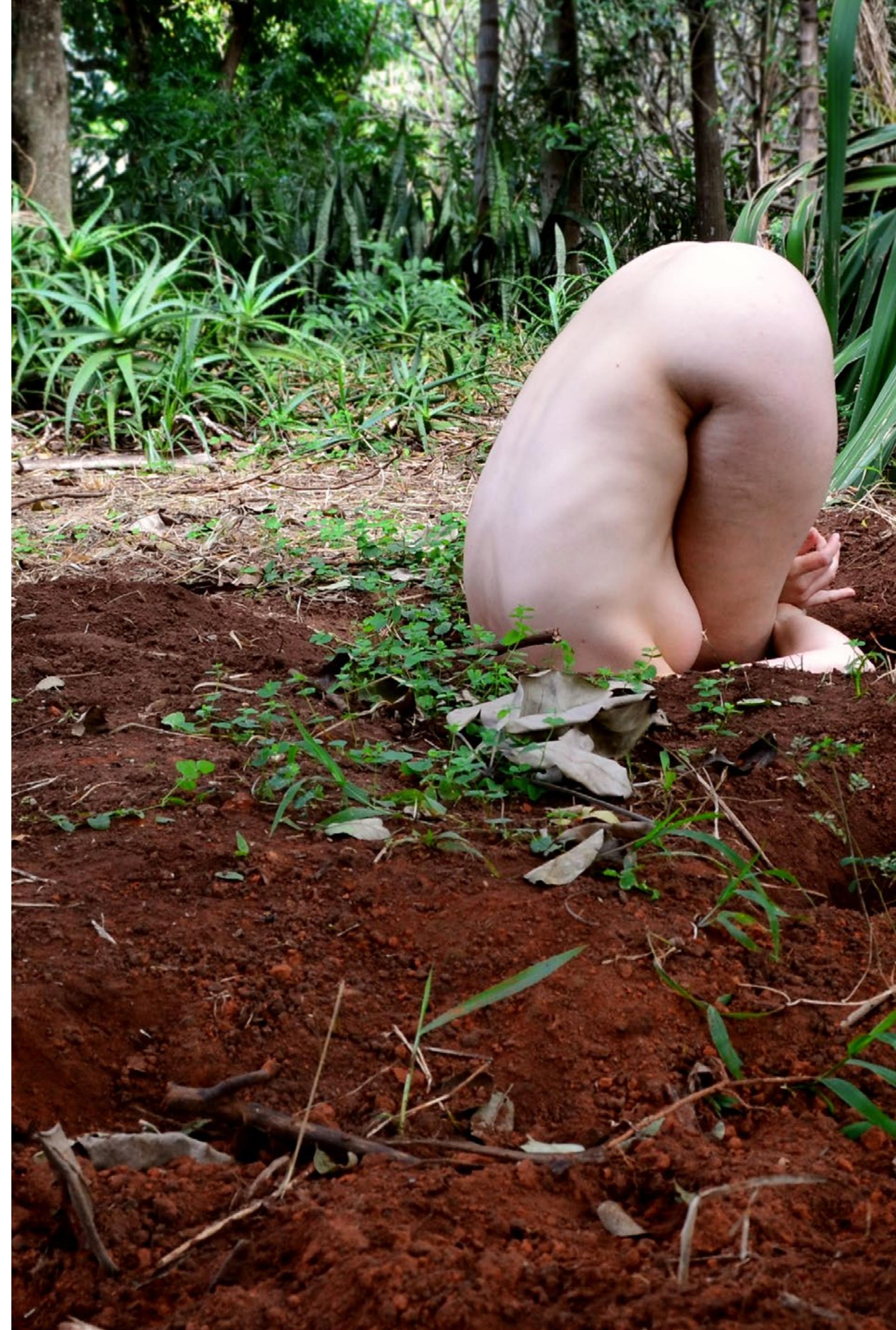




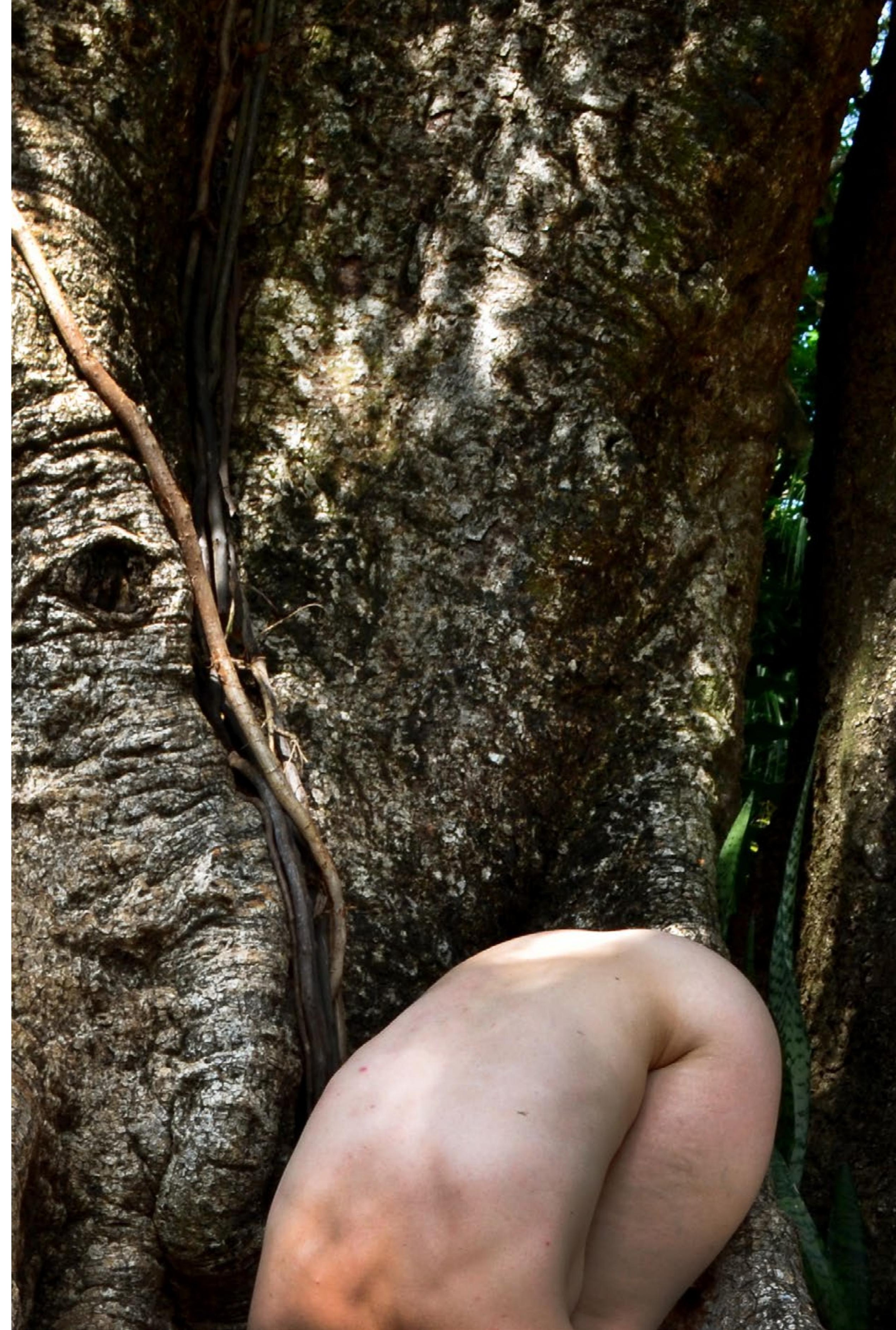




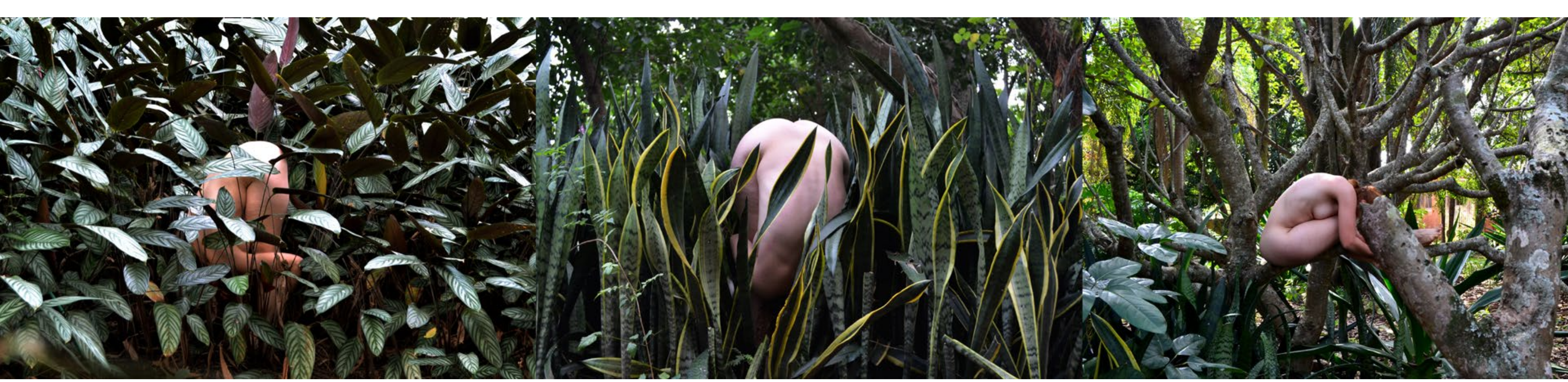

Da série Fotodobragens. Fotografia (tríptico). Jardim da Casa do Sol de Hilda Hilst. 


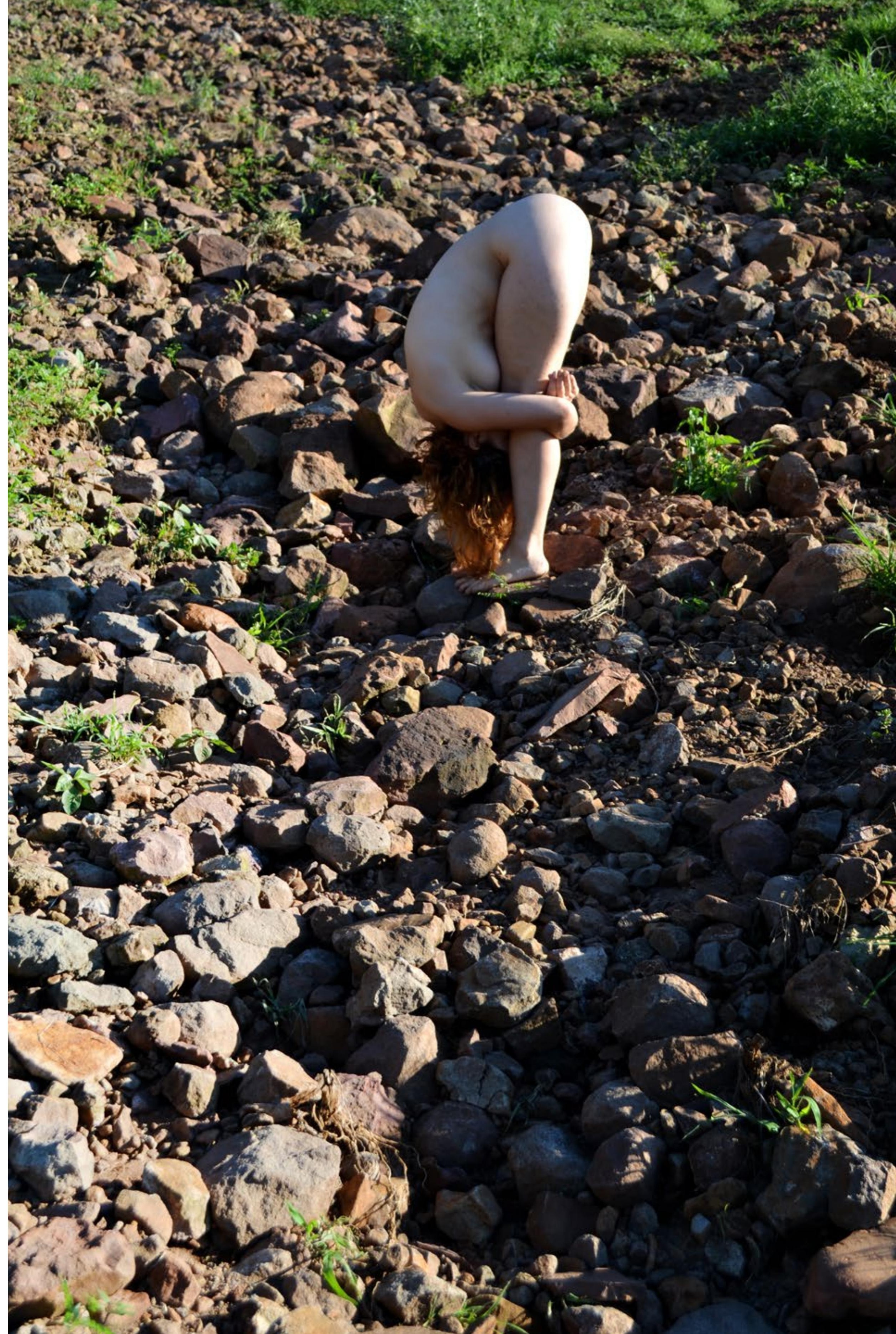


